\title{
Analisis Pengaruh Temperatur Input Terhadap Kekritisan High Temperature Gas Reactor Berbahan Bakar TRISO Dengan Pelapis Zirkonium Karbida
}

\author{
Wanda Feri Rezki ${ }^{1, *}$, Dian Fitriyani ${ }^{1 *}$, Ferhat Aziz $^{2}$ \\ ${ }^{1}$ Jurusan Fisika FMIPA Universitas Andalas \\ ${ }^{2}$ Pusat Sains dan Teknologi Bahan Maju Badan Tenaga Nuklir Nasional \\ *wandaferi9539@gmail.com*difiaal@gmail.com
}

\begin{abstract}
ABSTRAK
Analisis pengaruh temperatur masukan terhadap kekritisan High Temperature GasReactor (HTGR) telah dilakukan.HTGR yang diteliti berbahan bakar $\mathrm{UO}_{2}$ yang dilapisi TRISO dengan bahan pelapis berupa karbon pirolitik dan zirkonium karbida (ZrC). Variasi temperatur masukan $800^{\circ} \mathrm{C}-1600^{\circ} \mathrm{C}$ untuk bahan bakar dan temperatur pendingin dari $300^{\circ} \mathrm{C}-700^{\circ} \mathrm{C}$.Reaktor ini menggunakan gas helium sebagai pendingin dan parameter yang diamati adalah faktor multiplikasi efektif $\left(k_{\text {eff }}\right)$ pada teras reaktor.Penelitian ini dilakukan dengan komputasi menggunakan kode SRAC 2006 (Standard Thermal Reactor Analysis Code System) library yang digunakan yaitu JENDL-3.3. Teras Reaktor HTGR dibagi menjadi 8 region. Simulasi reaktor dilakukan dengan memvariasikan temperatur pendingin dalam setiap variasi temperatur bahan bakar, Dari setiap simulasi didapatkan faktor multiplikasi neutron dalam setiap variasi temperatur.Faktor multiplikasi neutron mengalami penurunan setiap kenaikan temperatur bahan bakar begitu juga dengan reaktivitas reaktor.Koefisien reaktivitas temperatur memenuhi standar yang ditetapkan oleh BAPETEN yaitu bernilai negatif.reaktor dalam keadaan kritis sempurna pada temperatur bahan bakar sebesar $1200^{\circ} \mathrm{C}$ dan temperatur pendingin sebesar $500^{\circ} \mathrm{C}$.

Kata kunci: faktor multiplikasi neutron, HTGR, temperatur, TRISOzirkonium karbida
\end{abstract}

\begin{abstract}
Analysis of the effect of input temperature on the criticality of High Temperature Gas Reactor (HTGR) has been carried out. The researched HTGR was fueled with $\mathrm{UO}_{2}$ coated with TRISO with coatings in the form of pyrolytic carbon and zirconium carbide $(\mathrm{ZrC})$. Variation in input temperature $800^{\circ} \mathrm{C}-1600^{\circ} \mathrm{C}$ for fuel and coolant temperature from $300^{\circ} \mathrm{C}-700^{\circ} \mathrm{C}$. This reactor uses helium gas as a coolant and the parameters observed are effective multiplication factors (keff) on the reactor core. This research was carried out by computation using the 2006 SRAC code (Standard Thermal Reactor Analysis Code System) used, namely JENDL-3.3. The HTGR reactor terrace is divided into 8 regions. The reactor simulation was carried out by varying the coolant temperature in each temperature variation of the fuel. From each simulation a neutron multiplication factor was obtained in each temperature variation. The neutron multiplication factor decreases every increase in fuel temperature as well as reactor reactivity. The temperature reactivity coefficient meets the standards set by BAPETEN which is negative. the reactor is in a perfect critical state at a fuel temperature of $1200^{\circ} \mathrm{C}$ and a coolant temperature of $500^{\circ} \mathrm{C}$. Keywords: neutron multiplication factor, HTGR, temperature, TRISO, zirkonium carbide
\end{abstract}

\section{PENDAHULUAN}

HTGR merupakan salah satu reaktor daya maju (advanced reactor) yang memiliki efisiensi termal yang tinggi serta mempunyai sistem keselamatan pasif yang melekat (inherent safety). Reaktor ini menggunakan grafit sebagai moderator dan reflektor, gas helium sebagai pendingin inert berfasa tunggal, bahan bakar partikel berlapis dan teras berdensitas daya rendah (Dewita dkk ,2017).

Bahan bakar untuk reaktor HTGR memilki dua bentuk yaitu berbentuk prismatik dan berbentuk bola. Bahan bakar berbentuk bola biasa disebut dengan kernel, bahan bakar ini terdiri dari lapisan pelindung berupa campuran pirokarbon dan silikon karbida ( $\mathrm{SiC}$ ) dan paduan tersebut biasa disebut dengan TRISO. Saat ini telah dikembangkan material pelapis bahan bakar TRISO menggunakan zirkonium karbida $(\mathrm{ZrC})$. $\mathrm{ZrC}$ lebih tahan panas dibandingkan silikon karbida (SiC) dan lebih tahan terhadap korosi kimia oleh produk fisi (Dewita, 2008).

Perancangan sebuah reaktor memerlukan beberapa analisis standar yang bertujuan untuk mengetahui keamanan dari sebuah reaktor, seperti jumlah daya yang dihasilkan, aspek neutronik, aspek termal dalam sebuah reaktor dan faktor keselamatan yang ada dalam reaktor tersebut. Salah satu analisis standar yang harus dilakukan adalah analisis neutronik yang 
berguna untuk mengetahui distribusi fluks neutron, faktor multiplikasi neutron, distribusi daya dan hal-hal yang berhubungan dengan perilaku neutron selama reaktor beroperasi.

Penelitian mengenai pengaruh temperatur terhadap kekritisan sudah banyak dilakukan. Aziz (2001) dalam penelitiannya mengenai analisis pasca-kritikalitas pertama pada reaktor temperatur tinggi HTR-10 China menyimpulkan bahwa dengan membandingkan pendingin yang digunakan yaitu helium dan udara, faktor multiplikasi neutron reaktor HTR-10 mengalami penurunan seiring kenaikan temperatur, baik dengan pendingin udara maupun helium, dan reaktor dikatakan mendekati kritis pada suhu $500^{\circ} \mathrm{C}$. Agustina (2010) dalam penelitiannya mengenai optimasi geometri teras reaktor dan komposisi bahan bakar berbentuk bola pada desain High Temperature Fast Reactor (HTFR) menyimpulkan faktor multiplikasi neutron mengalami penurunan seiring kenaikan temperatur, baik saat reaktor baru dihidupkan (beginning of life) maupun selama 800 hari penggunaan.

Penelitian mengenai bahan bakar TRISO dengan pelapis zirkonium karbida baru menganalisis kemampuan bahan zirkonium karbida sebagai penahan produk fisi (Dewita, 2008) sehingga memerlukan pengembangan lebih lanjut terhadap bahan bakar TRISO dengan pelapis zirkonium karbida perlu dilakukan untuk mengetahui pengaruh temperatur terhadap kekritisan reaktor HTGR dibandingkan dengan TRISO berlapis silikon karbida.

Penelitian ini menjelaskan tentang analisis pengaruh temperatur pendingin dan temperatur bahan bakar terhadap kekritisan HTGR berbahan bakar $\mathrm{UO}_{2}$ dengan lapisan TRISO salah satu bahan pelapis menggunakan bahan zirkonium karbida $(\mathrm{ZrC})$. Penelitian ini menggunakan variasi temperatur pendingin yaitu $300^{\circ} \mathrm{C}, 400^{\circ} \mathrm{C}, 500^{\circ} \mathrm{C}, 600^{\circ} \mathrm{C}$, dan $700^{\circ} \mathrm{C}$ dan variasi temperatur bahan bakar yaitu $800^{\circ} \mathrm{C}, 1000^{\circ} \mathrm{C}, 1200^{\circ} \mathrm{C}, 1400^{\circ} \mathrm{C}$ dan $1600^{\circ} \mathrm{C}$. Setiap variasi temperatur bahan bakar dilakukan 5 variasi temperatur pendingin.Penelitian dilakukan untuk mengetahui temperatur yang optimal dari reaktor HTGR dan mengetahui sistem keselamatan dari reaktor HTGR.

\section{METODE}

Reaktor nuklir yang digunakan adalah salah satu reaktor generasi IV yaitu reaktor temperatur tinggi berpendingin gas helium dengan spektrum neutron termal.Setiap variasi temperatur bahan bakar diberikan 5 variasi temperatur pendingin.Teras dibagi menjadi 8 region, 5 region aktif yang merupakan area bahan bakar dan 3 region terdiri dari pendingin, cladding, dan reflektor.

Simulasi komputasi yang digunakan pada penelitian ini menggunakan program SRAC (Standard Thermal Reactor Analysis Code). Proses komputasi SRAC diawali dengan menginputkan geometri sel, komposisi bahan bakar, komposisi pendingin, komposisi cladding, dan jumlah region yang kita butuhkan dalam PIJ, dari input PIJ tersebut didapatkan faktor multiplikasi infinity dan penampang lintang makroskopik. Setelah didapatkan penampang lintang makroskopik dan faktor multiplikasi infinity, geometri teras dan temperatur diinputkan pada citation, dari input tersebut didapatkan faktor multiplikasi efektif dan dilakukan pengulangan berdasarkan variasi temperatur pendingin dan temperatur bahan bakar. Dari hasil tersebut dilakukan analisis pengaruh temperatur terhadap kekritisan reaktor berdasarkan faktor multiplikasi efektif.Diagram alir prosedur perhitungan parameter neutronik menggunakan SRAC dapat dilihat pada Gambar 1 


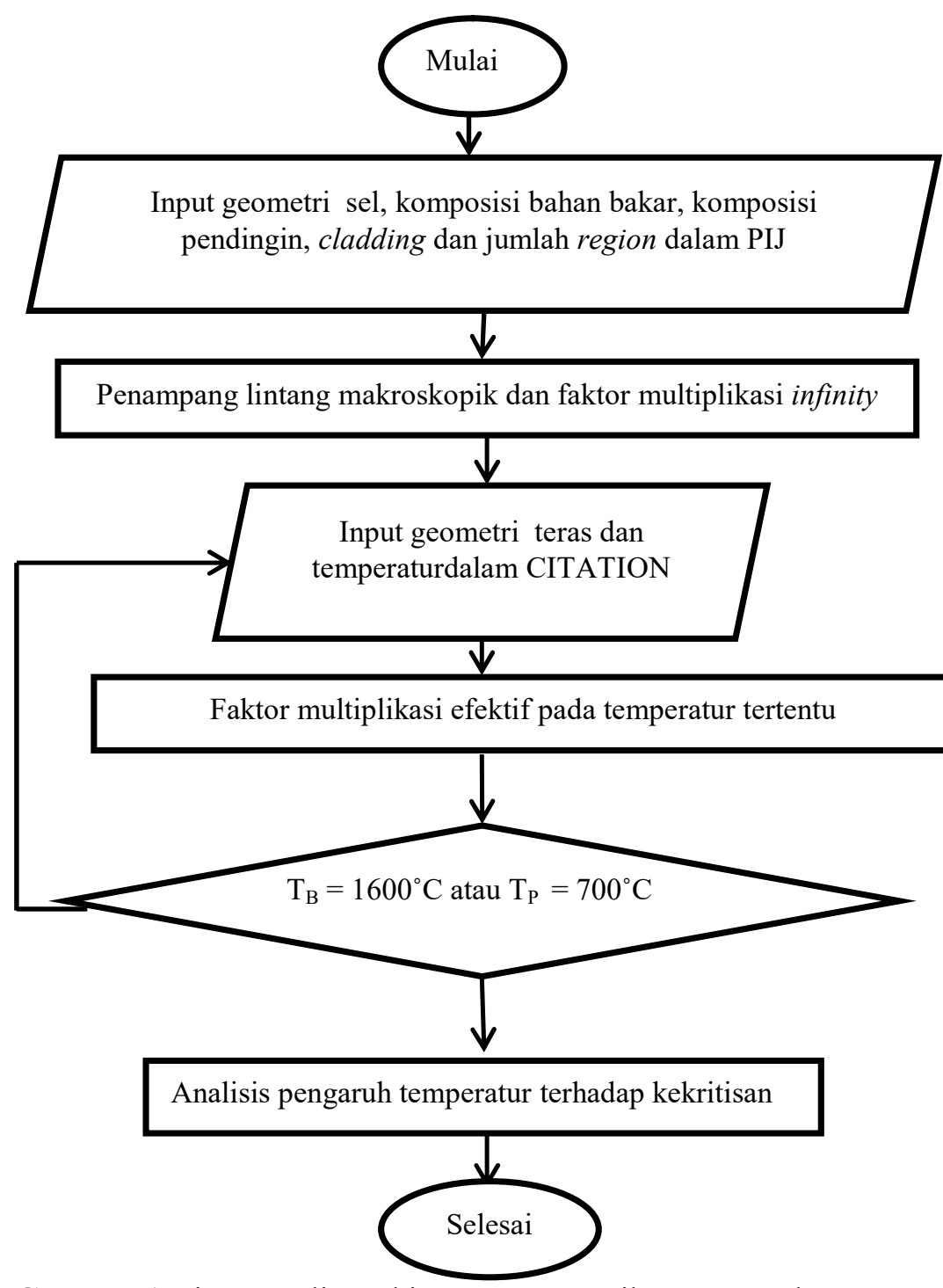

Gambar 1 Diagram alir perhitungan neutronik menggunakan SRAC

Reaktor HTGR terdiri dari 3 spesifikasi yaitu teras, bahan bakar dan moderator, dan lapisan TRISO.Spesifikasi teras reaktor, bahan bakar dan moderator dan lapisan TRISO dapat dilihat secara berturut-turut pada Tabel 1, Tabel 2 dan Tabel 3.

Tabel 1 Spesifikasi Teras

\begin{tabular}{cc}
\hline Parameter & Spesifikasi \\
\hline Daya termal & $30 \mathrm{MWt}$ \\
Geometri teras & Silinder (R-Z) \\
Bahan bakar & Pebble Bed \\
Pendingin & Helium \\
Reflektor & Grafit \\
\hline
\end{tabular}

(Sumber : Zuhair,2012) 
Tabel 1 Spesifikasi bahan bakar dan moderator

\begin{tabular}{|c|c|c|c|}
\hline \multicolumn{4}{|l|}{ Elemen Bakar : } \\
\hline \multicolumn{3}{|l|}{ Diameter bola } & $6,0 \mathrm{~cm}$ \\
\hline \multicolumn{3}{|c|}{ Diameter zona bahan bakar (Fueled Zone) } & $5,0 \mathrm{~cm}$ \\
\hline \multicolumn{3}{|c|}{ Densitas grafit di zona bahan bakar dan cangkang luar } & $1,84 \mathrm{~g} / \mathrm{cm}^{3}$ \\
\hline \multicolumn{3}{|c|}{ Muatan metal berat (Uranium) per bola } & $5,0 \mathrm{~g}$ \\
\hline \multicolumn{3}{|c|}{ Pengkayaan U-235 } & $17 \%$ \\
\hline \multicolumn{3}{|c|}{ Jumlah kernel bahan bakar dalam zona bahan bakar } & 165000 kernel \\
\hline \multicolumn{4}{|l|}{ Partikel Berlapis : } \\
\hline \multicolumn{4}{|l|}{ Fuel kernel: } \\
\hline \multicolumn{3}{|c|}{ Radius fuel kernel } & $0,025 \mathrm{~cm}$ \\
\hline \multicolumn{3}{|l|}{ Densitas $\mathrm{UO}_{2}$} & $10,4 \mathrm{~g} / \mathrm{cm}^{3}$ \\
\hline \multicolumn{3}{|l|}{ Lapisan : } & TRISO \\
\hline \multicolumn{4}{|l|}{ Bola moderator : } \\
\hline \multicolumn{3}{|l|}{ Diameter bola } & $6,0 \mathrm{~cm}$ \\
\hline \multicolumn{3}{|l|}{ Densitas grafit } & $1,84 \mathrm{~g} / \mathrm{cm}^{3}$ \\
\hline \multirow{2}{*}{\multicolumn{3}{|c|}{$\begin{array}{l}\text { Rasio bola bahan bakar terhadap bola moderator dalam teras } \\
\text { (Sumber : Aziz,2001) }\end{array}$}} & $57 / 43$ \\
\hline & & & \\
\hline \multicolumn{4}{|c|}{ Tabel 2Spesifikasi lapisan TRISO } \\
\hline \multirow{2}{*}{$\begin{array}{c}\text { Lapisan } \\
\text { (mulai dari kernel) }\end{array}$} & \multicolumn{3}{|c|}{ Parameter } \\
\hline & Material & Ketebalan $(\mathrm{cm})$ & Densitas $\left(\mathrm{g} / \mathrm{cm}^{3}\right)$ \\
\hline Pertama & Karbon berpori & 0,009 & 1,1 \\
\hline Kedua & Karbon pirolitik (PyC) & 0,004 & 1,9 \\
\hline Ketiga & Zirkonium karbida (ZrC) & 0,0035 & 6,6 \\
\hline Keempat & Karbon pirolitik (PyC) & 0,004 & 1,9 \\
\hline
\end{tabular}

\section{HASIL DAN DISKUSI}

Nilai faktor multiplikasi efektif merupakan perbandingan jumlah neutron yang dihasilkan dari setiap reaksi neutron dengan jumlah neutron dengan sebelumnya reaksi neutron.Faktor multiplikasi menunjukkan kekritisan dari suatu reaktor (Duderstadt, 1976). Hubungan faktor multiplikasi neutron dengan variasi temperatur bahan bakar dalam setiap variasi temperatur pendingin dapat dilihat pada Gambar 2

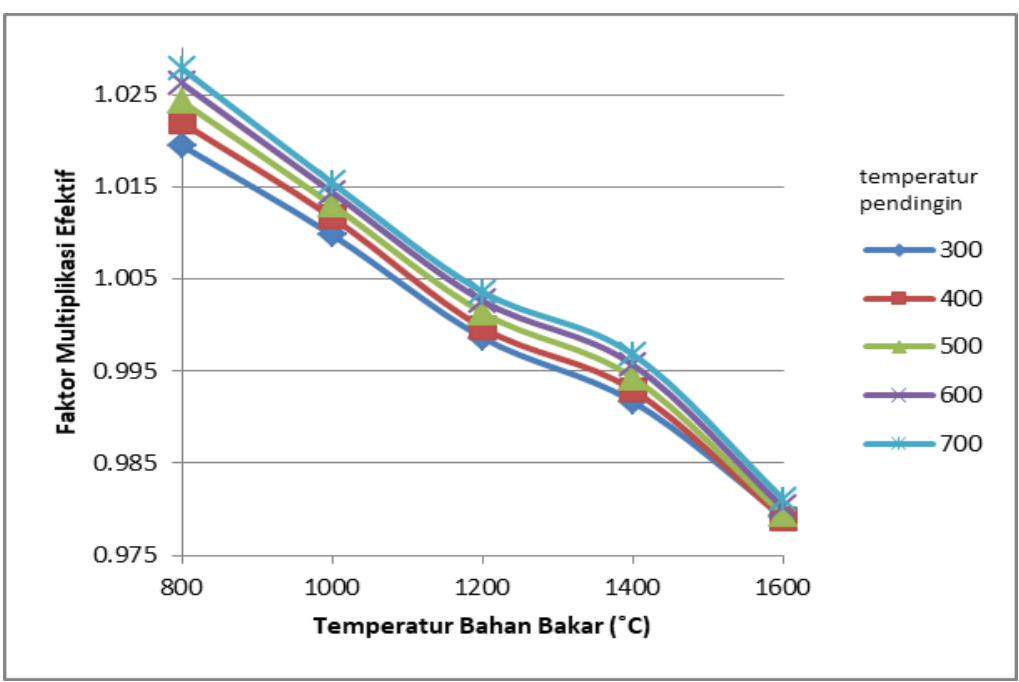

Gambar 2 Hubungan faktor multiplikasi neutron terhadap temperatur bahan bakar 
Berdasarkan Gambar 2, diperlihatkan bahwa reaktor dalam keadaan kritis walaupun ada beberapa keadaan yang menunjukkan reaktor dalam keadaan superkritis dan subkritis. Keadaan kritis reaktor HTGR dengan bahan bakar TRISO adalah nilai $k_{\text {eff }} \approx 1$ dengan reactivity swing (batas toleransi kekritisan) $\pm 0,02$. Faktor multiplikasi neutron mengalami penurunan dari setiap kenaikan temperatur bahan bakar.Hal ini disebabkan energi neutron mengalami penurunan sehingga penampang lintang fisi mengalami penurunan. Selain itu adanya efek doppler menyebabkan penampang lintang serapan mengalami kenaikan seiring kenaikan temperatur sehingga jumlah neutron juga mengalami penurunan seiring kenaikan temperatur (Lamarsh,2001).

Pengaruh kenaikan temperatur pendingin menyebabkan peningkatan dari faktor multiplikasi neutron itu sendiri, hal ini disebabkan oleh adanya pemuaian pada pendingin gas sehingga kemampuan pendingin untuk mengabsorbsi mengalami penurunan seiring kenaikan temperatur pendingin (Abdi,2018). Reaktor mendekati kritis sempurna $\left(\mathrm{k}_{\mathrm{eff}} \sim 1\right)$ adalah saat temperatur bahan bakar sebesar $1200^{\circ} \mathrm{C}$ dan temperatur pendingin $500^{\circ} \mathrm{C}$.

Nilai reaktivitas dari reaktor HTGR pada penelitian ini memiliki rentang nilai dari 0,025 sampai 0,025 , sehingga reaktor HTGR memiliki kestabilan yang tinggi.Nilai reaktivitas bergantung pada faktor multiplikasi neutron.Nilai faktor multiplikasi neutron mengalami penurunan disebabkan adanya efek pelebaran Doppler.Pelebaran Doppler menyebabkan tampang lintang serapan bahan bakar mengalami peningkatan.Namun, hal ini tidak disertai dengan banyaknya neutron yang lolos pada daerah resonansi.Peningkatan temperatur menyebabkan jumlah neutron yang lolos pada daerah resonansi semakin berkurang, sehingga neutron termal yang terserap oleh bahan bakar menjadi sedikit.Hubungan faktor multiplikasi neutron dengan variasi temperatur bahan bakar dalam setiap variasi temperatur pendingin dapat dilihat pada Gambar 3

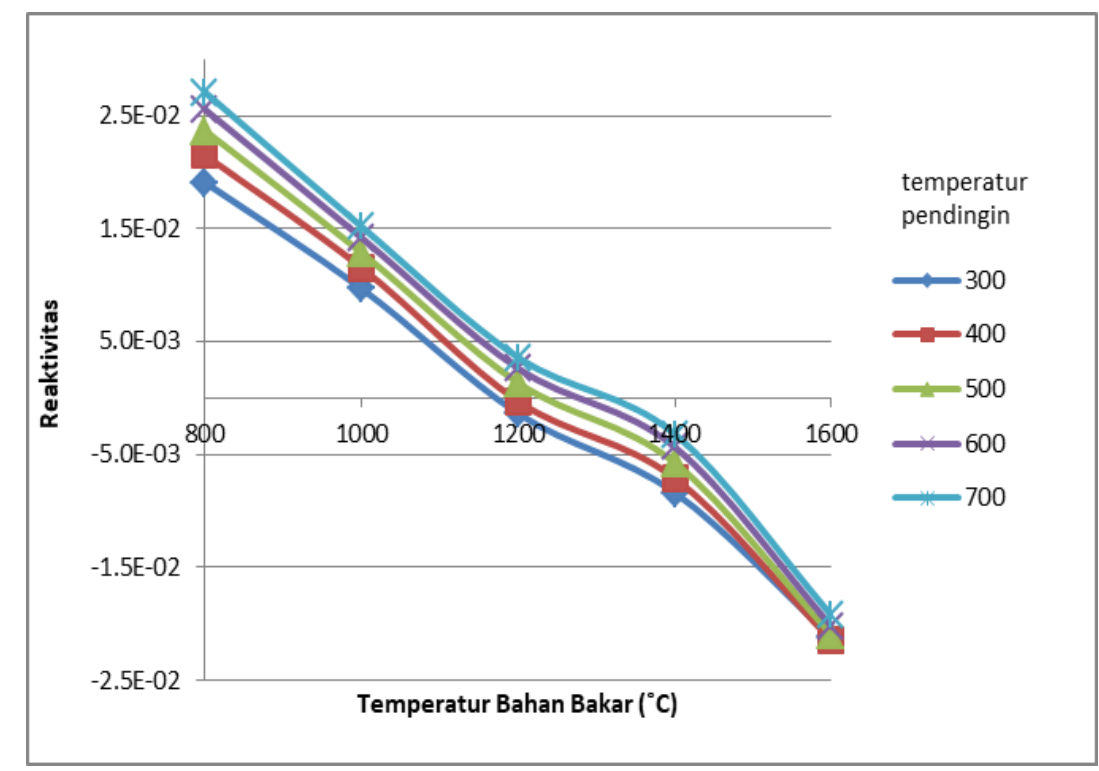

Gambar 3 Hubungan reaktivitas terhadap temperatur bahan bakar

Nilai koefisien reaktivitas temperatur menentukan faktor keselamatan pada reaktor, koefisien reaktivitas temperatur harus bernilai negatif hal ini memenuhi desain keselamatan inheren pada reaktor.BAPETEN mengizinkan reaktor yang memiliki nilai reaktivitas temperatur negatif, hal ini berdasarkan Peraturan Kepala Badan Pengawas Tenaga Nuklir (BAPETEN) Nomor 3 Tahun 2011 tentang Keselamatan Desain Reaktor Daya (Sasmita,2017). Koefisien reaktivitas temperatur negatif menyebabkan reaktor mengalami penurunan daya ketika temperatur dinaikkan.Dari hasil penelitian, reaktor HTGR memenuhi standar yang ditetapkan oleh BAPETEN.Hubungan koefisien reaktivitas temperatur dengan temperatur bahan bakar dapat dilihat pada Gambar 4. 


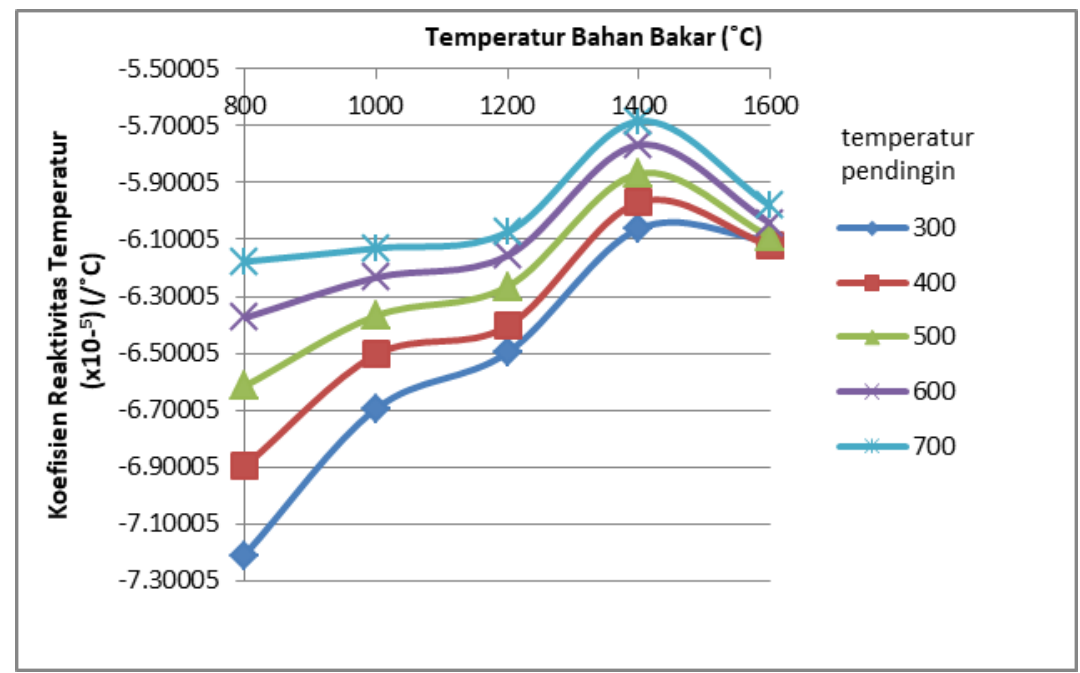

Gambar 4 Hubungan koefisien reaktivitas temperatur terhadap temperatur bahan bakar

\section{KESIMPULAN}

Setelah dilakukan perhitungan dan analisis neutronik didapatkan kesimpulan bahwaKenaikan temperatur bahan bakar menyebabkan penurunan faktor multiplikasi neutron, dan hal yang sebaliknya terjadi ketika temperatur pendingin mengalami kenaikan, Pada penelitian ini reaktor dalam keadaan kritis sempurna $\left(\mathrm{k}_{\text {eff }} \sim 1\right)$ yaitu pada temperatur pendingin sebesar $500^{\circ} \mathrm{C}$ dan temperatur bahan bakar $1200^{\circ} \mathrm{C}$. Reaktor HTGR pada penelitian ini memiliki kestabilan yang tinggi berdasarkan nilai reaktivitas yang didapatkan pada penelitian yaitu mendekati nol $(\rho \sim 0)$. Sistem keselamatan pada reaktor ini terdapat pada nilai koefisien reaktivitas temperatur, nilai koefisien reaktivitas temperatur bernilai negatif memenuhi standar keselamatan reaktor yang ditetapkan oleh BAPETEN berdasarkan PERKA Nomor 3 Tahun 2011.

\section{DAFTAR PUSTAKA}

Abdi, M., Sihana, dan Agung, A., "Analisis Neutronik High Temperature Reactor (HTR) dengan Bahan Bakar $\mathrm{UO}_{2}-\mathrm{ThO}_{2}$ tipe prismatik berpendingin ${ }^{7} \mathrm{LiF}-\mathrm{BeF}_{2}$ ", Prosiding Seminar Quantum Pendidikan Fisika (UAD, Yogyakarta, 2018), hal 713-723

Aziz, F., dan Lasman, A. N., "Analisis Pasca Kritikalitas Pertama Reaktor Temperatur Tinggi HTR-10 China", Prosiding Lokakarya Komputasi dalam Sains dan Teknologi Nuklir XII (BATAN,Jakarta, 2001), hal 25-40.

Dewita, E., Pengembangan Partikel Bahan Bakar Berlapis Untuk Reaktor VHTR, Jurnal Pengembangan Energi Nuklir, 10, 113-122 (2008).

Dewita, E., Alimah, S., Analisis Kinerja Bahan Bakar Reaktor Tipe HTGR Sebagai Penghalang Produk Fisi, Jurnal Pengembangan Energi Nuklir,19, 1-9 (2017).

Duderstadt, J. J., and Hamilton, L. J., Nuclear Reactor Analysis,(John Wiley \& Sons, Inc., USA., 1976) hal 75-76.

Sasmita, R., Q., J., Suharyana, Riyatun dan Khakim,A., "Analisis Nilai Koefisien Reaktivitas Suhu Bahan Bakar Dan Moderator Pada HTR-10", Prosiding Pertemuan dan Presentasi Ilmiah Penelitian Dasar Ilmu Pengetahuan dan Teknologi Nuklir (BATAN, Yogyakarta, 2017)hal 251-254

Lamarsh, J. R., and Baratta A. J., 2001, Introduction to Nuclear Engineering, (Prentice Hall, USA,2001), hal 374-388

Zuhair, Studi Desain Neutronik Perangkat Kritik Reaktor Temperatur Tinggi Berbahan Bakar Bola, Jurnal Penelitian Sains Universitas Sriwijaya, 15 - 21, (2012). 